\section{Development of insulin secretion in the human fetus}

The fetal development of the human $\beta$ cell has been described in histological and biochemical terms. In view of the potentially important role that insulin may play as an anabolic hormone in fetal growth, it is important to understand the secretory abilities of the human fetal endocrine pancreas. Glucose and arginine are ineffective stimuli of insulin secretion in utero at midterm (Adam et al., 1969; King et al., 1971), but at the same stage of development the $\beta$ cell has been shown to respond to a wide variety of stimuli in vitro (Milner, Barson, and Ashworth, 1971; Milner, Ashworth, and Barson, 1972). This paper reports the changes in the capacity of the human fetal pancreas to secrete insulin as a function of gestational age and body weight of the fetus.

\section{Material and methods}

Full experimental details have been described previously (Milner et al., 1971). Pancreas was taken from 30 dead human fetuses delivered by hysterotomy for the termination of pregnancy. The body weight of the fetuses varied between 83 and $625 \mathrm{~g}$ and their gestational age between 15 and 24 weeks. The pancreas was cut into pieces and incubated in a physiological buffer containing $0.6 \mathrm{mg}$ glucose $/ \mathrm{ml}$ or no glucose. After incubations lasting 90 minutes in which no measurement of insulin secretion was made, the pieces of pancreas were transferred to fresh flasks containing the same medium and incubated for 30 minutes. Insulin released into the medium in this period was measured by immunoassay and the mean insulin secretion was expressed as $\mathrm{pg} / \mathrm{mg}$ wet weight pancreas per $30 \mathrm{~min}$.

\section{Results}

The mean pancreatic insulin secretion in vitro was correlated with the body weight of the fetus (Fig.). Analysis of linear regression showed that the relation could be expressed by the formula: insulin secretion $(\mathrm{pg} / \mathrm{mg}$ pancreas per $30 \mathrm{~min})=334$ +1.75 body weight $(\mathrm{g})$, and that the correlation was significant at the $1 \%$ level. Analysis of mean insulin secretion as a function of gestational age revealed a correlation of the same level of significance.

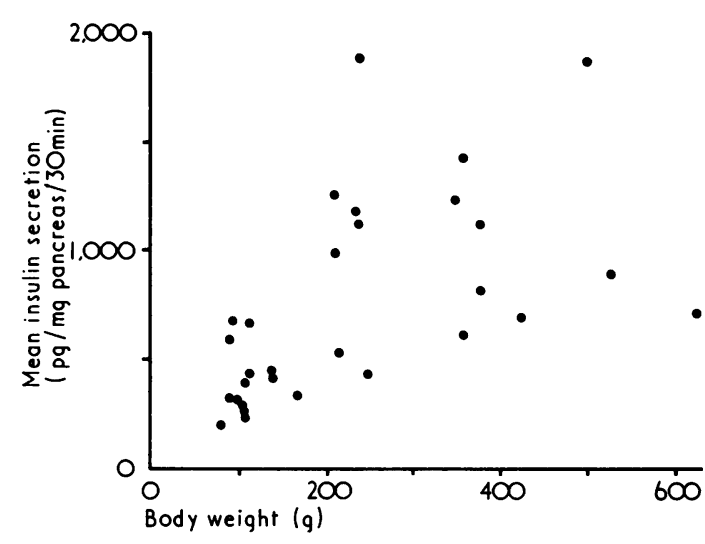

FIG.-Scattergram of mean pancreatic insulin secretion plotted as a function of body weight of human fetuses of 15 to 24 weeks' gestational age.

\section{Discussion}

The opportunity to study human fetal insulin secretion as a function of gestational age came from having performed a number of experiments designed to study the development of insulin secretion qualitatively in which the initial periods of incubation were performed under comparable conditions. The period chosen for the description of insulin release in vitro (91-120 min) was arbitrary but probably reflected insulin secretion under basal conditions since nonspecific insulin release occurs mainly in the first hour of incubation (Coore and Randle, 1964) and insulin release at the stage of development studied is independent of the extracellular glucose concentration (Milner et al., 1972). The demonstration of a linear correlation between insulin secretion in vitro and body weight or gestational age does not mean that insulin secretion in utero increases by equal amounts each month over the age range studied. However, it is probable that basal insulin secretion in utero does increase with advancing gestational age. In this respect man resembles the rabbit (Milner, 1969) and the rat (Asplund, Westman, and Hellerström, 1969) in which it has been easier to study the ontogeny of $\beta$ cell function.

It has been argued (Cheek and Greystone, 1969) 
that insulin promotes growth by stimulating protein synthesis and thereby the size of cells. This study has shown that the period in which insulin secretion has been shown to rise coincides with that in which cellular growth takes place mainly by cellular division (Widdowson, Crabb, and Milner, 1972). This is followed at about the 30th week by a period in which growth occurs largely by an increase in cellular size. These findings are neither contrary to nor in support of Cheek and Greystone's hypothesis. It is possible that insulin secretion increases in the period studied due to a preferential development of $\beta$ cells within the islet or of islets within the pancreas. Alternatively, the change could be of secretory activity within each $\beta$ cell. If insulin has an anabolic role in the fetus it is interesting to note that the stage of development in which pancreatic insulin secretion increases precedes that in which cells grow by increase in size.

\section{Summary}

Insulin release from pieces of human fetal pancreas incubated in vitro was found to be correlated with the body weight and gestational age of the fetus between weeks 15 and 24 of fetal life.

We are grateful to Professor J. A. Davis for his encouragement and to our gynaecological colleagues for their generous co-operation. This work was supported by the British Diabetic Association and the Medical Research Council.

\section{REFERENCES}

Adam, P. A. J., Teramo, K., Räihä, N., Gitlin, D., and Schwartz, R. (1969). Human fetal insulin metabolism early in gestation. Response to acute elevation of the fetal glucose concentration and placental transfer of human insulin-I-131. Diabetes, $18,409$.

Asplund, K., Westman, S., and Hellerström, C. (1969). Glucose stimulation of insulin secretion from the isolated pancreas of foetal and newborn rats. Diabetologia, 5, 260.

Cheek, D. B., and Greystone, J. E. (1969). The action of insulin, growth hormone, and epinephrine on cell growth in liver, muscle, and brain of the hypophysectomized rat. Pediatric Research, 3, 77.

Coore, H. G., and Randle, P. J. (1964). Regulation of insulin secretion studied with pieces of rabbit pancreas incubated in vitro. Biochemical fournal, 93, 66.

King, K. C., Butt, J., Raivio, K., Räihă, N., Roux, J., Teramo, K., Yamaguchi, K., and Schwartz, R. (1971). Human maternal and fetal insulin response to arginine. New England fournal of Medicine, 285, 607.

Milner, R. D. G. (1969). The secretion of insulin from foetal and postnatal rabbit pancreas in vitro in response to various substances. Fournal of Endocrinology, 44, 267.

Milner, R. D. G., Ashworth, M. A., and Barson, A. J. (1972), Insulin release from human foetal pancreas in response to glucose, leucine and arginine. Fournal of Endocrinology, 52, 497.

Milner, R. D. G., Barson, A. J., and Ashworth, M. A. (1971). Human foetal pancreatic insulin secretion in response to ionic and other stimuli. Fournal of Endocrinology, 51, 323.

Widdowson, E. M., Crabb, D. E., and Milner, R. D. G. (1972) Cellular development of some human organs before birth. Archives of Disease in Childhood, 47, 659.
M. A. Ashworth, F. N. LeACH, and R. D. G. MILNER*

Department of Child Health, University of Manchester, St. Mary's Hospital, Manchester.

*Correspondence to Dr. R. D. G. Milner, St. Mary's Hospital, Manchester 13 OJH.

\section{Clinical assessment of gestational age in the neonate}

The scoring system of Dubowitz, Dubowitz, and Goldberg (1970) for the clinical assessment of gestational age in newborn infants was used in the assessment of 522 consecutively examined neonates from the Obstetric Landings and Special Care Baby Unit of the Jessop Hospital for Women, Sheffield.*

All infants were assessed within 48 hours of delivery and, whenever possible, without prior knowledge of gestational dates from the obstetrical notes.

\section{Case material}

In the study there were 264 male and 258 female infants.

From data obtained from the routine maternity notes on menstrual cycles and 'last menstrual period' it was found that 434 normal neonates $(218$ males and 216 females, including 5 sets of twins) were born to mothers with certain dates and regular 28-day ( \pm 2 days) cycles, who were not taking oral contraceptive preparations in the month before conception.

Of the remaining infants, 85 were born to mothers with uncertain dates, irregular cycles, or on oral contraceptives. 3 infants with major abnormalities at birth were assessed but the results were not included in the analysis.

\section{Results}

The scoring system was easy to apply, and after initial practice could be used during routine neonatal examination and without reference to charts illustrating the criteria. It took between 5 and 10 minutes to complete an assessment.

Normal infants. For all normal neonates where the gestation by dates was certain the difference between assessment by dates and by score was one week or less in 400 infants. The difference

\footnotetext{
*This scoring system is based on a combination of 11 external criteria as originally delineated by Farr, Kerridge, and Mitchell (1966), and 10 neurological criteria selected for their ease of elicitation, reliability of inter-observer assessment, and consistency, irrespective of the state of the infant.
} 